\title{
ESPACIOS DE ESPIRITUALIDAD: EL MONASTERIO DE MORERUELA
}

\author{
POR \\ María Luisa Bueno DomíngueZ \\ Profesora Titular de Historia Medieval, UAM.
}

\section{RESUMEN:}

Santa María de Moreruela fue un monasterio de la Orden Cisterciense en tierras zamoranas. El estudio parte de la ubicación de este monasterio, que considero importante para poder acercarnos, por medio de la soledad del lugar, a los elementos básicos de la vida monacal: Soledad, silencio y pobreza. No se trata de estudiar el monasterio citado, sino que, a través de él, se pueda uno encontrar con la esencia y el espíritu del monacato. Transmitir que el silencio permite al monje escucharse a si mismo y ponerse en contacto en su intimidad con Dios.

Palabras ClaVE: Moreruela, Císter, Aislamiento, Silencio, Claustro, Pobreza, Monje,

\section{ABSTRACT}

Santa María de Moreruela was a Monastery of the Cistercian Order built in Zamora lands..

This study starts in the situation of this monastery that I consider it is important to approach us -by means of the solitude of the place- to the basic rules of Monastic life: it is said Loneliness, Silence and Poverty.

This work doesn't pretend to study the monastery in itself but to find through it, the essence and spirit of monastic life.

I want to tansmit that the Silence allows the monks to hear to themselves and to get in touch with their private life with God.

KEY WORDS: Moreruela, Cister, Loneliness, Silence, Solitude, Poverty, Monk, Cloister

Recibido/Received 10-03-2006

Aceptado/Accepted 15-07-2006 
La Edad Media es una época de contrastes extremos y, por lo tanto, de posturas y formas de vida que se caracterizan por ellos. Esto es más evidente cuando ésta se produce en espacios reducidos. Sin lugar a dudas, de todos ellos el monasterio constituye un mundo, un universo muy especial, un universo completo. Recinto cerrado al exterior, recinto alejado del mundo externo, y allí dentro de sus muros, una forma de vida peculiar, que se refleja en las construcciones. La vida en su interior tiene como objetivo fundamental y básico llegar a Dios a través de la pobreza. Es decir, una búsqueda de Dios por el camino necesario de la pobreza. Esta es la base de la vida monástica. Como opción de vida, el monacato no es ajeno a las circunstancias de quienes se incorporan a él, gentes acuciadas por la necesidad, enfermedad o miedo ante un delito cometido. Hay una tensión entre el ideal del monje y la biografía de cada uno de ellos antes y después de su ingreso en el monasterio.

Esos hombres buscaban a través de una vía de perfección, de la austeridad, y de la pobreza que les permitiera lograr su destino: encontrarse con Dios. Esa búsqueda, siendo libre, no era fácil. A la perfección espiritual se llegaba por una vía ardua, por sendas estrechas. No se puede estudiar un monasterio sin tener presente la ascesis, la lucha continua de los monjes para perseverar en su decisión y recorrer el camino para alcanzar su meta. En el monasterio hay algo más que una regla, es eso y unos hombres que la acatan. Esto es lo que permite entender el espacio religioso en el que viven. Ser monje era renunciar a la propia voluntad. El monje renuncia a su individualidad para convertirse en un ser comunitario. Una forma privilegiada de esa renuncia es la preocupación por el alma y la vida espiritual y la concepción de su condición corporal: su cuerpo es el ataúd que contiene su osamenta hasta que Dios quiera llevarlos junto a Êl.

Esta descripción de lo que es el ideal del monje coexiste con el hecho de que las condiciones sociales llevaran a algunos a hallar en el monasterio la única o la mejor forma posible de sobrevivir ante la amenaza de la enfermedad, la pobreza, el peso de la culpa o el miedo al castigo por algún delito cometido. En los escritos cistercienses se recogen también los motivos que llevaron a muchos a la conversión: la enfermedad, la pobreza, el hallarse en cautividad, la sospecha de que se descubra cualquier infamia, el peligro de la vida presente, el temor o la visión de las penas del infierno, la renuncia al mundo, el deseo de la patria celestial ${ }^{1}$. El monasterio, según los casos, mantiene su finalidad espiritual o es un modo de vida seguro, pero incluso para éstos existe la posibilidad de un proceso de «conversión» que puede hacer de ellos buenos monjes. En los mo-

\footnotetext{
${ }^{1}$ Diálogo de Milagros de Cesáreo de HeIsterbach, Introducción, versión y notas Zacarías Prieto Hernández, Zamora, Monte Casino 1998, p. 98. Este monje del siglo XII y XIII nos aporta datos muy importantes acerca de la vida en los monasterios. A través de los milagros conocemos los temores y muchas supersticiones de la Edad Media.
}

Hispania Sacra, LIX

119, enero-junio 2007, 35-50, ISSN: 0018-215-X 
nasterios se dio, al menos en los años centrales de la Edad Media, siglos XI y XIII, esta variopinta y diferente aportación de personas en la comunidad.

\section{EL NOVICIADO COMO CAMINO DE CONVERSIÓN}

El novicio se preparaba en el ejercicio fundamental y más importante de la vida monástica, la Lectio Divina. Necesitaba saber leer y comprender lo que estaba leyendo. Lo leído tiene que ir directamente al alma, al espíritu del monje. El hábito de la lectura que le llevará a sentir el texto desde la quietud, desde la concentración, aprendiendo a deletrear el texto como si realmente hablase, y a llevarlo a la meditación ${ }^{2}$.

En el noviciado el futuro monje aprende además a desprenderse de sí mismo mediante la disciplina, la obediencia y la vida común. En el monasterio, a diferencia de la sociedad, no hay privilegios. Todos los monjes tienen las mismas obligaciones.

«La gloria presente pierde su valor, se menosprecia la flor de la juventud; no se tiene en cuenta la nobleza; se considera como locura la sabiduría del mundo; no se complace ni de la carne ni de la sangre; se renuncia al amor de los parientes y seres queridos; se desprecia como basura los privilegios, honores y dignidades para ganar a Cristo» ${ }^{3}$.

En la sociedad medieval la violencia forma parte de la vida, el servicio de armas se considera como el de mayor prestigio, se pensaba que el monacato era un refugio para encubrir y esconder a quienes no servían para las armas. El monje se ejercitaba en la batalla de su conversión ${ }^{4}$. Sin embargo los hombres dedicados a los combates y torneos pudieron considerar que «quien hasta los doce años no sabe montar a caballo y sigue en la escuela sólo sirve para ser clérigo» 5 .

${ }^{2}$ La lectio divina «es un ejercicio lento, integral, intuitivo, sapiencial, receptivo, desinteresado». J. M ${ }^{\mathrm{a}}$ de la Torre, Presencia Cisterciense; memoria, arte, mensaje Zamora, Monte Casino 2000, pp. 368 y ss.

3 San Bernardo a Godofredo de Perone y a sus compañeros, Obras Completas, VII Cartas, CIX, Edición Bilingüe, Biblioteca de Autores Cristianos 505, Madrid, Editorial Católica 1990, pp. 412-417. Se dirige a unos jóvenes de importancia que han decidido entrar en la vida monástica, y, por tanto, les enseña muy claramente que en el monasterio desaparece todo lo que se fue en el mundo y de paso les incita a ser verdaderos monjes «Fomentad, pues, la perseverancia única corona de las virtudes. No pronunciéis un sí o un no ambiguo, para ser hijos de vuestro Padre del cielo, en quien no cabe mudanza ni sombra de variación...».

${ }^{4} \mathrm{C}$ de Heisterbach, Diálogo... La conversión produce un cambio en el sentido de iniciar una vida nueva, abierta incluso a quienes ingresaron en el monasterio con otro fin.

${ }^{5}$ Poesía de Trovadores $=$ trouvères $=$ minnesinger $:$ de principios del siglo XII a fines del siglo XIII, antología, edición bilingüe de Carlos Alvar, Madrid, Alianza Editorial 1982, p. 31, hace referencia a este pensamiento, para indicar que aunque se diese un valor importante a los trovadores y muchos no- 
El monasterio es un conglomerado de gentes que mantienen sus vidas en un recinto cerrado al exterior. Importa, pues, en primer lugar llegar los hombres, a las personas que los habitaron más que las consideraciones económicas, es decir, al sentido que dieron a su vida y su convivencia

\section{LOS ESPACIOS DE UBICACIÓN: MORERUELA}

Un monasterio benedictino, asentado en unos parajes que hoy se nos presentan gratos e idílicos, ante parte de sus muros derrumbados, evoca más que las tierras que un día fueron posesión suya y hasta donde extendió sus límites, más que su economía, el cómo vivían, por qué se esforzaban, qué sentían y a qué aspiraban los monjes. Al pensar en ellos entendemos que los monasterios se encuentran allí donde mejor pueden realizar su vocación, en la soledad y la pobreza.

El monasterio se halla en un lugar apartado de los núcleos de población. El monje necesita la soledad para vivir en el silencio, que le permite la comunicación con Dios. Habitar en un sitio alejado, no pisado por otros hombres, conduce a otro aspecto de la vida monacal, que deriva de la soledad: el trabajo. Había que acondicionar la tierra. Se talaron árboles, se desecaron las tierras. Soledad y trabajo implican pobreza voluntaria. Tenemos así los tres elementos asociados al monasterio medieval: soledad, pobreza y trabajo.

El monasterio de Santa María de Moreruela es un buen ejemplo. En 1042 el monarca Fernando I dona a un tal Kelnahaze unas tierras y le obliga a que, cuando muera, se las entregue al monasterio de Santiago de Moreruela ${ }^{6}$. Pocos datos tenemos de este momento señalado porque Moreruela adquiere importancia como monasterio de la orden Cisterciense a mediados del siglo XII.

Pudo dar permiso San Bernardo para revivir Moreruela, porque realmente no iba a ser una fundación, que resultaría muy costosa No se ha tratado lo suficiente el esfuerzo que suponía llevar a cabo una fundación por parte de las órdenes monásticas en la Edad Media. Era una labor tan costosa y difícil que, a veces, resultaba imposible. Pues una fundación requería tener el suficiente personal y un lugar donde se pudiera contar por lo menos con un edificio que per-

bles e hijos de caballeros se formasen en las letras, la verdad era que se prefería antes que nada que el noble se educase en las armas, función que se consideraba la más noble de todas.

${ }^{6}$ Archivo Histórico Nacional (AHN) Clero, carpeta 3548, documento $\mathrm{n}^{\circ} 7$, «...sic concedimos tibi ea ut habeas ea et possideas ea ovni vite tue post obitum vero tuum ut relinquas ea inlesa et intemerata ad partem ipsius monasterio Sancti Iacobi apostoli de Moreroila», Véase mi estudio «El monasterio de Moreruela de 1143 a 1300, Zamora, Caja de Ahorros Provincial de Zamora, 1975, Doc. No 1., p. 125.

Hispania Sacra, LIX

119, enero-junio 2007, 35-50, ISSN: 0018-215-X 
mitiera empezar con un coste no muy elevado ${ }^{7}$. No era el caso de Moreruela ${ }^{8}$. A San Bernardo España le parecía un lugar demasiado lejano y difícil. Quizás Moreruela fue posible porque contaba con una construcción aunque venida a menos.

En 1143, Alfonso VII donó a su gran amigo y colaborador Ponce de Cabrera una villa «Moreruela de Frades». Posiblemente en ese lugar existiera un monasterio y unos monjes. Estaba despoblado, o al menos sin organizar porque el rey se refería a ella como villa «desertam». Ponce de Cabrera se encargó de reconstruir y restaurar el monasterio casi íntegramente ${ }^{9}$. Desde este momento empieza el desarrollo material y espiritual del monasterio. En muchas ocasiones, a lo largo del siglo XII, se menciona el monasterio como cauterio del reino, lo que indica el concepto que se tiene de él desde el punto de vista espiritual: es un centro purificador.

Moreruela reunió desde un principio todas las características de un monasterio cisterciense. Ofrecía a los monjes el espacio adecuado: lugar apartado de cualquier núcleo poblacional, tierra cubierta de agua, de maleza, como atestigua la documentación. Facilitaba a los monjes blancos aislamiento, silencio, la soledad. Los monjes podían realizar el «ora» y el «labora» ${ }^{10}$, que hacen posible la quietud del alma a través del silencio, el alejamiento del mundo, la intimidad $^{11}$. El silencio pedido por San Bernardo permitía, en un lugar como Moreruela, tener los ojos y la mente abiertos para comunicarse con Dios y escucharle. El silencio habitual y la ausencia del ruido invitaban a meditar en las

7 «Me han dicho que tratas de erigir una abadía en España con tu santa comunidad. Lo cual me admira sobremanera: ¿qué razones, qué intención, qué utilidad te mueve a desterrar a tus hijos a un lugar tan lejano, que tantas expensas y trabajos va a costar encontrarlo y edificarlo, cuando puedes encontrar otro más cercano ya construido y preparado para recibirlos?». San Bernardo-Artaldo, abad de Prully, Obras Completas, VII Cartas, LXXV..., pp. 283-285.

8 «Es difícil sobre todo porque no hay tanto personal como en otras ocasiones. Además de los grupos de dos o tres personas que han sido destinadas a diversos lugares desde que nos separamos de vos se han formado íntegramente tres nuevos monasterios y me quedan aún otros más para fundar en fecha próxima», Obras Completas, VII Cartas, CLXXXV ... 612-613. Se dirige al papa Inocencio II al que le pone de manifiesto que no puede enviarle los monjes que le ha pedido alegando lo que he señalado más arriba, que no tiene gente suficiente.

${ }^{9}$ AHN Clero. Doc. n 10, Año 1143.Véase mi estudio El monasterio..., documento n ${ }^{\circ}$ 3., p. 126.

${ }^{10}$. En ella hace una defensa de lo que más apreciaba en su vida, y en general en la vida del monje; que se le respetase el silencio y la soledad «No soy yo una persona que sólo es digna de las tinieblas del claustro, y que sólo debo ser juez, árbitro y acusador de mí mismo, para que mis obras correspondan a mi profesión, y a mi nombre de monje corresponda una vida solitaria»? San Bernardo-canciller Aimeric, Obras Completas, VII Cartas, XLVIII, pp. 216-221.

${ }^{11}$ Es fácil imaginar estos aspectos cuando se visita el lugar que ocupa el monasterio de Moreruela donde el silencio se deja oír en todas las partes haciendo de él un elemento básico del lugar y que nos acerca mucho más a la vida del monje en ese entorno. 
realidades celestiales. El monje debía amar el silencio porque a través de él se producía en la mayor intimidad el encuentro con Dios. ¡Qué bueno es expresar en silencio al Señor! En el silencio y la esperanza reside vuestra fortaleza ${ }^{12}$.

\section{LOS ESPACIOS COMUNITARIOS}

La regla de San Benito definía perfectamente todos los ámbitos de convivencia del monasterio, y en ellos, como puede imaginarse, la iglesia era fundamental. En ella el monje realiza la oración. La de Moreruela es de tres naves. En ella aparece la organización jerárquica propia de la sociedad medieval. Jerarquía en la composición de la comunidad y jerarquía en la iglesia. Por eso la comunidad de monjes ocupa la parte más cercana a la parte principal. Detrás, sus miembros que están enfermos, y el más alejado de todos para los conversos, que viven aparte de la comunidad, incluso tienen su entrada concreta ${ }^{13}$. El edificio se levantó en la parte más elevada del terreno, pues es el centro del monasterio.

El claustro presencia la vida cotidiana por sus galerías Restos del claustro se perciben en nuestro monasterio. Es fácil imaginar deambulando a los monjes por él. Está muy cerca de la iglesia y es el lugar de la lectio divina y la meditación en el silencio ${ }^{14}$. El silencio permite a cada monje encontrarse con la propia identidad y buscar a Dios, centro de la vida monástica.

La lectio divina es una de las tareas más arduas en la existencia del monje. Pide toda su atención. El silencio y la soledad de su vida hacen que eso sea posible, le proporcionan la atmósfera que necesita para encontrarse consigo mismo. La lectura del texto implica un gran esfuerzo, porque no se trata de que los

\footnotetext{
12 Cuando San Bernardo cree cercana su «inmutatio» y se sentía acompañado por la oración de sus hermanos monjes y la misericordia de Dios, creyó justificada su decisión de no salir del monasterio más que para la reunión anual de los abades del Císter. «Sedebo et silebo, si forte experiar quod de plenitudine intimae suavitatis sanctus Propheta erectuat: bonum est... expectare Dominum in silentio. Et ne solus videamini mihi lusisse, puto iam non audebitis me de hoc silentio meo reprehendere et more vestro appelare sopores quod, ut puto, congruentius ac magis proprie sanctus Isaias cultum justitiae nominat, et de quo legistis in hoc ipso propheta, dicente Domino: In silentio et spe erit fortitudo vestra». San Bernardo-Pedro de Cluny, ibidem CCXXVIII, 720-723. Considero que es importante conocer el pensamiento de San Bernardo y ponerlo en conexión con los lugares donde se ubican los monasterios del Cister, porque es indudable que ambos aspectos, el propio concepto sobre el silencio y el lugar de estos monasterios forman una unidad. La percepción del silencio creaba un ambiente propicio para la oración.

${ }_{13}$ J. M ${ }^{\mathrm{a}}$ DE LA ToRre, Presencia..., p. 353. En este estudio explica con toda clase de detalles la composición y ordenación de los espacios monacales y nos acerca a los espacios de convivencia a través de la realidad y del simbolismo, Ibidem pp. 350-384.

14 Todos estos aspectos se pueden observar de la lectura de las cartas de San Bernardo que constituyen un aporte muy importante para el conocimiento de la vida de los monjes desde el punto de vista de la espiritualidad.
}

Hispania Sacra, LIX

119, enero-junio 2007, 35-50, ISSN: 0018-215-X 
ojos se desplacen por el texto, sino de extraer del texto la máxima luz. Isaac de Stella ${ }^{15}$ nos cuenta cómo se hace lectio. Los monjes vuelven fatigados de trabajar las tierras, pero aún les queda por hacer lo más arduo, lectio en el claustro. Para desbrozar este campo y no sembrar entre los espinos «chorreamos de sudor, con este sol de mediodía que además, nos quema. Así pues, después de estar tan fatigados por la semilla terrestre, reposamos a cubierto de la encina acogedora que veía cerca de aquí. Allí cribaremos, moleremos, amasaremos, coceremos y comeremos no sin sudor interior a la semilla de la palabra divina» ${ }^{16}$.

El monje debe hacer la lectio con gusto, debe identificarse con lo que lee, asumirlo realizándose preguntas para plantearse las respuestas en su intimidad. Es un esfuerzo físico, porque en esa lectura el monje va deletreando. Es una lectura meditada con la voz y pronunciada que exige mayor concentración. El monje que lee en voz alta criba y muele con sus labios la palabra de Dios. Lee y a la vez se escucha y medita.

Por eso el claustro es un espacio muy sereno, carente de ruido ambiente adecuado para la lectura y la meditación. Se dice que es semejante a un molino porque en él el monje muele la palabra de Dios. En el claustro el monje realiza estas operaciones: sede, es decir, se sienta en profundidad porque efectivamente esa postura supone quedarse con uno mismo. Luego, tolle, coge la carne de la Palabra, su texto, en el cual lege, que incluye tres aspectos: ver con los ojos del cuerpo, ver con los y del corazón, y deletrear, que, en definitiva, es saborear el texto. El deletreo lleva a otro elemento, el audi, es decir oír lo que se deletrea. Tras estos actos, viene la meditación, moler hasta meter en el corazón, el espíritu del texto ${ }^{17}$.

\footnotetext{
15 De origen inglés, monje, hombre sociable y muy amante del saber, había entrado en contacto con gentes intelectuales, entre ellos con Abelardo. En el año 1147 enseñaba con seriedad y responsabilidad en la escuela de Poitiers. Parece que hay un intento de demostrar que cuando las gentes se tomaban la vida con seriedad, con sentido de responsabilidad se refugiaban en un monasterio. Avanzado el siglo XII Isaac decide entrar en el monasterio de Pontigny, uno de los primeros surgidos de la orden del Cister, y allí vive con rigor, con austeridad y con dureza la vida monacal. En el monasterio el hombre se inicia, renace para trabajar y trasciende hacia Dios. Este sería su pensamiento sobre el monje.

${ }^{16}$ Georges Duby, San Bernardo y el arte cisterciense (El nacimiento del gótico), Madrid, Taurus 1981, pp. 105-106. Un aspecto importante es que en el Cister se compaginan dos realidades, la individual, personal y única; con la colectiva, que es la que separa al hombre de oración del hombre del trabajo. Un lugar saneado desde el punto de vista material y una comunidad que trata de limpiar su vida para que pueda fructificar la semilla del evangelio: «Unos abaten árboles, otros tallan piedras, otros construyen muros y otros desvían un brazo del río para instalar caídas de agua; éstas hacían girar las máquinas para los bataneros, los curtidores, los herreros y los demás obreros; después, habiendo limpiado la casa, volverán al río de donde procede y devolverán lo que había tomado».

17 Juan María DE LA Torre, Presencia cisterciense..., pp. 370-372.
} 
La sala capitular no es muy amplia en el monasterio de Moreruela. Severa en su sencillez, se comunica con el claustro. En ella se reúnen todos los monjes presididos por el abad tras el oficio. Se reúnen los monjes, se distribuye entonces el trabajo de cada jornada, y se realiza la confesión. Es un momento de comunidad intenso.

Es el escenario donde el monje escucha al abad, acepta el trabajo y las disciplinas para purgar sus pecados y se educa así en la obediencia. En la reunión capitular cada monje expresa, mientras los demás guardan el máximo silencio, en voz alta sus faltas contra la Regla, la obediencia y humildad. ¿De qué puede acusarse a un monje? ¿Qué tentaciones no vencidas o vencidas hay en el monasterio? Sea cual sea la respuesta, el monje sabe a quien dirigirse en la prueba. «Si sientes el aguijón de la tentación, mira la serpiente de bronce colgada del madero y sorbe, no en las heridas, sino en los pechos del Crucificado» ${ }^{18}$.

Tientan al monje el diablo, su propia mente y la lujuria. El diablo es peligroso porque conoce muy bien los resortes para hacer tambalear el edificio de la fe. Sabe sobre quién actuar y cómo hacerlo. El monje conoce que se presenta cuando menos se espera. Los textos hablan del diablo como el primer enemigo. La mente le tienta con la memoria de las delicias del mundo que ha dejado fuera, fomentando los deseos de la carne. La lujuria es «esa desordenada y deshonesta profanación del alma y de cuerpo a causa de los deseos impuros» ${ }^{19}$, normales y casi cotidianos. En todas las tentaciones actúa el diablo.

La vida monacal exige renunciar al placer, la riqueza, la gloria y el contacto, físico y mental con las mujeres. Esta lucha es constante y el arma del monje es la oración ${ }^{20}$. Las personas que optaron por este tipo de vida sabían que alcanzar la perfección en ella no se lograba sin pagar un alto precio. Corrían el riesgo de cansarse, de desanimarse por sentirse sin fuerzas, sin motivos. Expresión de ese

18 «Que la austeridad de la Orden no atemorice tu tierna edad. Piensa que un cardo lleno de espinas hace suavísima la lana, y que la práctica religiosa acelera la conciencia. Cuenta con la dulzura de Cristo, y la harina del Profeta te hará sabroso el más amargo potaje. Si sientes el aguijón de la tentación, mira la serpiente de bronce colgada del madero», San Bernardo a Hugo novicio, luego abad de Bonneval, Obras Completas, VII Cartas, CCCXXII, pp. 962-964.

19 «Que hijas de la lujuria son: el egoísmo propio, el odio a Dios, el afecto desordenado a los placeres del siglo, el miedo y desesperación de la vida futura, la irreflexión, la inconstancia y la ceguera de la mente», C.de Heisterbach. Diálogo..., p. 363.

${ }^{20}$ Pone de manifiesto como los que son carnales y del siglo, los que viven según la carne, de ellos se dice impropiamente que son tentados, pues tan pronto como sienten tentación, consienten en ella o la resisten muy tibiamente. Son semejantes al caballo o al mulo, que no tienen inteligencia, sino que hay que sujetar sus quijadas con bridas y frenos, porque no se acercarán a Dios. Si pues, tentación es la vida de los religiosos, quienes con vigilias, ayunos oraciones, con obediencia tanto en lo próspero como en lo adverso, en absoluta pobreza de las cosas de este mundo terrenal por Cristo, 1levando siempre la contraria a sus vicios y concupiscencias, es necesario que estés de acuerdo en que la tentación es la satisfacción por los propios pecados, Ibidem pp. 268-269.

Hispania Sacra, LIX

119, enero-junio 2007, 35-50, ISSN: 0018-215-X 
estado de ánimo era el ausentarse del rezo de las horas, distraerse o dormirse en los oficios divinos. Eso que se juzgaba un pecado de pereza, lo debía de confesar el monje. Había que vigilar para que no se quebrantara la Regla. Durante la lectio, un monje se encargaba de vigilar a los demás, como vemos en la denuncia que recogen algunos sermones, que hablan de aquellos que en el claustro dejan caer la cabeza sobre su libro, roncan en la iglesia durante los oficios, duermen en la sala capitular mientras se expone la doctrina. Ojalá fueras frío o caliente, pero como eres tibio comenzaré a vomitarte de mi boca ${ }^{21}$.

Hay testimonios que hablan de que por excesiva tristeza se cae en la desesperación. Hubo en algunos monasterios monjes que se arrojaron a estanques o a $\operatorname{pozos}^{22}$. ¿Por qué motivos? Nunca lo sabremos. Quizás el silencio excesivo fuese para algunos un auténtico martirio. Para otros sería difícil olvidar del todo la vida que habían dejado, sobre todo en quienes pertenecían a la nobleza. No era fácil soportar la ansiedad que crea el esfuerzo ascético contra la nostalgia de los que se ha dejado engrandecido o supervalorado por la austeridad y la pobreza monacales: los vestidos, las largas vigilias, los rigores del invierno y del verano.

Cada monje guardaba el secreto de sus propios afectos. El apego a las personas no debe entrar en la vida de los monjes. La buena comunicación entre ellos se veía mal. San Bernardo se alejó voluntariamente de su buen amigo Guillermo de St. Thierry, porque entre ellos se había producido un afecto, una complicidad, que el propio Guillermo debió de manifestar en algún momento como tristeza por la falta de respuesta de aquél a quien tanto admiraba que se vio obligado a responder: «Me aseguras que te quiero menos que tú a mí23.

El refectorio era quizás un recinto amplio. Como en los demás espacios comunitarios, presidía el abad rodeado por los más ancianos de la comunidad. Reunidos todos, se bendecía la mesa y se sentaban en silencio en mesas toscas de madera. Tomaban su frugal escasa comida sin ruido, mientras escuchaban un pasaje de Regla ${ }^{24}$. En las proximidades del refectorio estaban el lavatorium, la

21 «...En verdad la acidia es la tristeza que nace de la turbación de la mente y de ella proviene la malicia y desesperación. El monje acidioso provoca náuseas a Dios y a sus ángeles», Ibidem, p. 306.

22 «Cuando hablo de esta clase de tragedia tan nefastas me resisto a pronunciar los nombres de los lugares o personas y el de la Orden para que nadie piense que quiero desacreditar a aquellos religiosos.» Ibidem, p. 311.

23 «Tú no sé con qué confianza afirmas tan rotundamente refiriéndote no sólo a tu corazón, sino al mío, «cuanto más amo, menos amado soy» Estas son tus palabras y preferiría que no fuesen tuyas, porque no sé si son verdaderas... ¿Cómo puedes probar que tu me amas a mí más que yo a ti?». Respuesta de San Bernardo a las quejas de Guillermo, abad de Saint Thierry, Obras Completas, VII Cartas LXXXV, pp. 318-323. En realidad lo que se aprecia es que Guillermo no recibe ni una sola carta de Bernardo, ni una muestra de cariño, ni un recuerdo a través de los mensajeros que llegaban del monasterio de San Bernardo.

${ }^{24}$ La dieta que ellos ponían en marcha parece haber sido decisivo para hacer de los monjes personas más longevas que los que comían de otra forma. 
cocina y el calefactorium. En el lavatorium se rasura a los monjes y en el calefactorium se reservaba a los monjes cuya debilidad necesitaba el alivio de un lugar templado y caldeado. Aquí cuatro veces al año, en febrero, abril, junio y septiembre, el monje se extraía sangre, a veces hasta dos litros 25 .

$\mathrm{Al}$ dormitorio acude el monje después de que la comunidad ha rezado Completas, caída la noche y cuando las puertas del monasterio se han cerrado al exterior. La noche es el momento más peligroso. En el dormitorio, ubicado siempre en la parte superior, arderá una lámpara. En el descanso el monje deja la oración y el trabajo, el ora et labora, por eso puede ser tentado por el demonio que le acecha siempre. Los monjes duermen vestidos y con las capuchas puestas como si estuvieran en una sepultura ${ }^{26}$.

Éstos son los espacios básicos de convivencia del monasterio. No lo abandonará el monje hasta la hora de su muerte. Hay también espacios transitorios por donde el monje pasa en algunas ocasiones y donde sólo no permanece algún tiempo. La enfermería se colocaba en la zona más apartada del monasterio. En ella se atendía también a los ancianos. Los que están en ella no están obligados a guardar la dieta que prescribe la Regla. El hermano enfermero proporciona remedios rudimentarios, naturales, como la aplicación de las hierbas cuyas propiedades curativas conoce. En Moreruela, desde el siglo XIII, constantemente ardían unas lámparas, debido a una promesa del abad Esteban de Moreruela con el arcediano de Zamora en Toro, Pedro Pérez, en 1250. Había donado éste a la abadía tres pares de casas en la ciudad, en el lugar de «figolorum», con la obligación de mantener permanentemente encendida la enfermería. Si no se hacía, los bienes deberían ser devueltos al cabildo $^{27}$. Una de las funciones de monasterios fue la de caridad en el más amplio sentido de la palabra hacia los desposeídos. Con la hospedería cumplía esa obra de misericordia justificando de ese modo los bienes que el monasterio poseía. El hermano hospedero acogía a los que llegaban de fuera. «Nosotros los monjes estamos obligados por mandato de la Regla a recibir a todos los huéspedes que nos lleguen como si fuera al mismo Jesucristo. Y si les ne-

\footnotetext{
${ }^{25}$ Era un hábito en la Edad Media que partía de una equivocación: creer que la sangría purificaba el cuerpo y el cerebro, y, como tal eliminaba los aspectos negativos.

${ }^{26}$ C.de Heisterbach, Diálogo... El dato de que duermen con la capucha puesta se puede deducir de los ejemplos o milagros que relata el autor al que me vengo refiriendo repetidamente. Aporta a través de los milagros que expone las formas de vida que se daban en los monasterios, las costumbres y los ritos, considerándole un libro fundamental para acceder a un conocimiento más profundo de la Edad Media.

${ }^{27}$ Archivo Catedral de Zamora (ACZ). Tumbo negro folios 135v 136r. «donat infirmitorio ipsius Monasterii ad opus luminarium infirmorum tria paria domorum... lumen continuum de nocte infirmis predicti monasteri».
}

Hispania Sacra, LIX

119, enero-junio 2007, 35-50, ISSN: 0018-215-X 
gáramos la hospitalidad, quiénes ahora tachan a la orden de avaricia entonces la tacharían más de impiedad y de falta de misericordia» ${ }^{28}$.

\section{LOS MONJES Y SU TRABAJO}

El trabajo de los monjes tiene dos aspectos: el material y el espiritual. En las comunidades cistercienses se daba un equilibrio entre el ora y el labora

No era fácil que se aceptara el trabajo material, pues «a Dios no le place que los valerosos caballeros, filósofos sutiles elocuentes doctores, que porque hayan renunciado al mundo, sean obligados como viles esclavos a realizar trabajos pesados y poco convenientes» ${ }^{29}$.

La documentación del monasterio de Moreruela nos da datos sobre las malas condiciones de las tierras donde se asentó y esto implicó la necesidad de mejorarlas El trabajo, más que una identificación con el medio rural, cumplía con un requisito fundamental en la vida del monje: vivir en la humildad y la obediencia, mediante el sacrificio que exigía el labora ${ }^{30}$. Con la puesta en buen estado de las tierras los cistercienses rendían culto a Dios y vivían la pobreza realizando una actividad servil. De modo que el propio acondicionamiento del lugar para poder vivir hacía posible mortificarse en el camino de perfección buscado.

\footnotetext{
28 «Lo que ellos llaman avaricia, nosotros lo llamamos providencia.... Apenas si hay casa alguna de la Orden que no tenga deudas bien sea a causa de los pobres o de los huéspedes o también por el número de los que cada día entran en religión y no se les puede rechazar sin escándalo» C. de HEISTERBACH, Diálogo... Segunda distinción, cap. LVII, p. 326.

${ }^{29}$ George Duby cita este pensamiento de Orderico Vital que evidencia el disgusto de la opción de vida de los primeros cistercienses. Por otra parte hace un importante y substancioso camino por todos los comentarios que despertaba, entre personajes del mundo monacal, la presencia de los cistercienses, y especialmente el hecho de que los monjes trabajasen como vulgares campesinos. En definitiva a través de estos comentarios se aprecia claramente como en la sociedad medieval se acepta muy mal que se realicen funciones que no son propias del estamento y la idea sobre el monje es muy clara; la principal función del monje es la meditación y la oración, vid. San Bernardo y el arte cisterciense ..., p. 75.

${ }^{30}$ G. Duby, San Bernardo..., p. 66, pone de manifiesto este aspecto diciendo cómo el trabajo para los Cistercienses no era una degradación, un medio por el que adquirían esa pobreza tan necesaria al monje, Pero quizá sea a través del propio San Bernardo donde uno encuentre un mayor acercamiento a este problema del trabajo. «Porque la desocupación engendra desgana, el trabajo hambre y el hambre, misteriosamente, vuelve dulce lo que el aburrimiento hace insípido. Las legumbres, las habas, las pastas de harina, el pan de cebada con agua fastidian al indolente, pero son las delicias del trabajador», ... y más adelante «Si trabajas manualmente durante el día cuanto te exige tu profesión, muy agria será la comida para no comerla a gusto», esto se lo dice a su sobrino Roberto que cambió la orden Cisterciense por la de Cluny, véase carta 1, p. 57. Véase mis estudios «El monasterio... ob. cit.; Dejando hablar a la Edad en la Edad Media entre lo real y lo imaginado, cap III; Isabel ALFONSO AnTón, La colonización cisterciense en la meseta del Duero: el dominio de Moreruela (siglos XII al XIV), Zamora, Instituto de Estudios Zamoranos «Florián de Ocampo», 1986.
} 
Los cistercienses se encontraron un lugar boscoso, lleno de humedad, con una gran charca o quizá muchas. Eran los dueños de unas tierras que nadie quería y todos consideraban lugares insalubres. Supieron los cistercienses transformar lo que era insano en saludable. En aquellas la desolación de las tierras, que tanto asustaban a las gentes, consiguieron los cistercienses acondicionarlas con su trabajo. El esfuerzo realizado por los primeros monjes hizo de Moreruela un lugar no sólo habitable sino próspero.

¿Qué encontraron en Moreruela los cistercienses del siglo XII?31. En 1143 los monjes tuvieron que acondicionar el lugar, dominar el bosque, quitar los matorrales, desecar la humedad. Modificaron el paisaje. Sólo ellos sabían cómo desecar el terreno. Lo necesitaban para cimentar la abadía. Sabían además que, desecado el terreno, obtendrían una excelente tierra para el cultivo. Mostraron tenacidad y sabiduría. La riqueza del monasterio, la abundancia de posesiones, la organización de las mismas proceden no sólo a la generosidad de los donantes sino que son también fruto del trabajo y esfuerzo que los monjes y conversos realizaron sobre la tierra.

$\mathrm{Al}$ monasterio, cercano al río Esla, se sumaron tierras en Castrotorafe, Riego del Camino, Manganeses de la Lampreana, Tábara. Este núcleo inicial fue creciendo por donaciones reales. Estas se debían a los servicios que los abades prestaban a los monarcas colonizando las tierras y engrandeciendo el reino y también a las donaciones de quienes creían eran un medio eficaz para hacerse perdonar las culpas a través de la penitencia y oración de los monjes.

De esta manera fue desbordándose el primitivo núcleo de propiedades en la las proximidades del Esla y del monasterio y creciendo su posesiones en la cuenca del río Tera, en las tierras de Valderaduey y en la cuenca del Duero. El patrimonio se extendió hasta Miranda, en Portugal.

Esta gran dimensión del patrimonio ¿no podía romper con una de las obligaciones de los monjes del Císter, es decir con la estabilidad en el monasterio? ¿No entrañaba una dificultad para vivir estrictamente la Regla, trabajar tierras tan lejanas? Podríamos responder que debieron haber rechazado todas las tierras que les llegaban, pero esa solución olvida que las donaciones tenían motivos religiosos: para poder dar limosna y en sufragio de los donantes. Los monjes tenían conciencia de ser los intermediarios entre Dios y los hombres. En cuanto la lejanía de las tierras, al igual que en los demás monasterios del Císter,

\footnotetext{
${ }^{31}$ Véase mi estudio «El monasterio...» De este modo, el grupo de monjes «roturadores», «agrónomos», «colonizadores», aplicando de modo literal los principios de la Regla conseguirían, sin proponérselo, unos excedentes de producción extraordinarios a los que dieron obligada salida mediante el comercio, obteniendo unas ganancias que invertirían en la expansión de su patrimonio». Isabel ALFONso ANTón La colonización cisterciense en la meseta..., p. 270. Es muy interesante para este aspecto de la evolución y expansión del monasterio todo el capítulo V.
}

Hispania Sacra, LIX

119, enero-junio 2007, 35-50, ISSN: 0018-215-X 
se recurrió a los conversos que formaban parte de la comunidad, observaban la regla, pero no tenían las mismas obligaciones con respecto a la oración del coro, y no se les exigía estabilidad en un monasterio. Estos hermanos, generalmente de extracción humilde, servían a Dios contribuyendo a la transformación del medio y al buen cultivo de las tierras. Se resolvió así el problema de la explotación de estas amplias posesiones.

Fundamentales para la abadía fueron las tierras de cereales. Los cilleros eran numerosos y conocidos, se situaban en lugares privilegiados: Toro, Villafáfila, Tordehumos, Villalpando, Benavente, Zamora, Salamanca. Se trabajaron las tierras para dedicarlas al cultivo de las viñas, lográndolo en tierras donde no se esperaba obtener este rendimiento. Un milagro basado en el trabajo. La huerta de San Froilán o de los monjes blancos era famosa no sólo en Zamora sino en todo el reino. No faltaba el agua, el río estaba cerca y es muy posible que en el monasterio gracias hubiera agua corriente.

Numerosas granjas cubrieron un amplio territorio que no dejó de crecer desde el 1143 hasta 1230. Moreruela de Suso, Santa Colomba, Requejo, Felgoso, Villafáfila componen un ejemplo de las veintidós que organizaron ${ }^{32}$. Estas granjas eran unidades agrarias al frente de las cuales colocaron a un maestro, un converso que las administraba. En cada una podían vivir de diez a quince conversos dirigidos por el maestro. Dedicadas a la explotación de las tierras o a otras actividades como podía ser la ganadería, supusieron un cambio importante. Las gentes podían ver las viñas bien trazadas, en perfectas hileras. Cuanto mayor era la ordenación de las tierras, mayor el número de monjes, mayor era la extensión de las tierras cultivadas, más necesario se hizo perfilar bien la marcha del monasterio con cargos que estarían al frentes de los diversos aspectos de su vida.

Se necesitan personas idóneas para asegurar el buen funcionamiento de todas y cada una de las explotaciones. Por eso el papel de los cilleros fue fundamental. Eran los administradores y controlaban el trabajo de los conversos. Las tierras deben rendir el cien por cien. Supervisaba la administración de todas las propiedades y, junto con el abad, se sabía qué tierras debían adquirirse. Se explica de este modo que la riqueza del monasterio, la abundancia de posesiones se debía no sólo a la generosidad de los donantes sino también al trabajo y esfuerzo que los monjes y los conversos ${ }^{33}$.

Otro cargo importante fue el de despensero. Su obligación fundamental era que no faltase jamás, en la despensa de la abadía, especialmente los vegetales, que componían la parte esencial de la dieta. Las cubas de vino estaban siempre

\footnotetext{
${ }^{32}$ Ibidem
}

33 Ibidem. 
repletas pero con uno de peor calidad que el que se vendía. Cuidaba de la proveer para hacer el pan, la leña necesaria para la cocina.

Fray Diego de Sanabria, como celarero en la cocina disponía de todo lo que la comunidad necesitaba, Diego de Saludes cuidaba de la sacristía. Su misión fundamental era ocuparse de todo lo concerniente al culto, los ornamentos litúrgicos, las túnicas que debían vestir según los días. Monjes y conversos tenían sus vestimentas propias ${ }^{34}$.

Los cistercienses de Moreruela lograron un gran patrimonio que llegó hasta tierras de Portugal, con el cultivo de cereales, viñedos, la ganadería, pesquerías... como queda documentado. El monasterio era mucho más que una empresa económica. Era un centro de espiritualidad importante. Esta es su dimensión fundamental. Los monjes, con su forma de vida, combatían con armas espirituales. Es la otra parte del lema cisterciense, el ora, que justificaba la vida monástica. El oficio divino regido por las siete horas canónicas dividía la vida del monje, como la de todos los seres en la Edad Media, en dos grandes jornadas, el día y la noche, con las oraciones cada tres horas y las misas por los donantes.

Además de la oración y del culto, Moreruela era visto por la gente como un centro de caridad, de atención a los pobres. Es el segundo motivo de los donantes. Donaciones que no se hacen para que Moreruela fuese un poder económico, sino porque se cree que es un centro de poder espiritual.

Los enterramientos en Moreruela eran un privilegio buscado por esta razón. Numerosos personajes obtuvieron ese bien extraordinario que les acercaba más a los privilegios espirituales. Descendientes de los Ponce de Cabrera, Fernando Ponce de Cabrera, que en año 1196 hacia una gran donación al monasterio, donación que llevaba implícita la petición de ser enterrado en Moreruela, tan pronto como se anunciara su muerte ${ }^{35}$.

Cuando Juan Vela, hijo de Sancha Ponce de Cabrera y de Vela Gutierrez, muere en el año 1181, se elige un monasterio digno de su persona, de su linaje. No había en este momento en Zamora un monasterio más importante y famoso, y a la vez más familiar, que el de Moreruela. Su abuelo lo restauró. El monasterio estaba para gloria del reino de León, pero especialmente para gloria de esta familia, que lo elegirá en muchas ocasiones como lugar para el descanso definitivo.

34 A.H.N. Sección Clero. Carpeta 3555 documento n 16. Año 1311. Transcribe Isabel Antón, ob, cit., p. 528. Documento muy interesante desde el punto de vista material pero para mi trabajo fundamental porque da a conocer algunos cargos administrativos, del monasterio, Así Pedro Malva, celarero mayor y fray Diego Benayes, cantor enfermero de los pobres, e fray Miguel de Riego enfermero del convento, fray Miguel de Bretou, visitario, fray Diego de Saludes sacristán mayo, fray Diego de Sanabria, celarero de la cocina etc., pp. 531-532.

35 A.H.N Clero Moreruela, carpeta 3550 doc. no 3 . Véase El monasterio..., doc. № 32, p. 154. En realidad nos encontramos ante una restitución que hacía Fernando Ponce de todo lo que tenía en San

Hispania Sacra, LIX

119, enero-junio 2007, 35-50, ISSN: 0018-215-X 
Juan Vela fue enterrado en el claustro del capítulo junto a la puerta de la Iglesia en el arco que estaba al lado del altar de San Juan. Enterrarse en un lugar digno para perpetuarse pensando, quizá, que en lugar tan importante como ése, reafirmaba lo que se fue en vida, pues eso no se perdía ni siquiera con la muerte. Los Ponce consideran Moreruela parte de su patrimonio. Sus hermanos, Fernando Vele, Poncio Vele Y Pedro Vele, se encargaron de cumplir la voluntad de Juan y llevar su cuerpo al monasterio ${ }^{36}$. El monasterio recibió importantes bienes materiales, pero para los donantes lo realmente importante eran las oraciones de los monjes y ser enterrados lo más cerca posible de ellos como garantía para obtener la salvación eterna.

Alfonso Méndez de Travanca, el conde don Pedro y don Felipe, habían sido enterrados en Castrotorafe en 1307. Doña Herma de Alemania, su esposa y su madre, donó a la abadía cuantiosos bienes. Estos bienes llegaban a la abadía como riquezas demoradas, pues sólo se disfrutaría de ellas una vez que la condesa hubiese muerto. Sin embargo la obligación que adquiría el monasterio, en función de estos bienes, debía ser inmediata. La condesa pedía al abad Jaime que sacase de sus enterramientos, en Castrotorafe, a su esposo e hijos y que les diera sepultura en el monasterio. Allí, según lo pactado por el abad y la condesa, debía ser enterrada ella Todos debían descansar en el claustro, lugar que ella misma eligión ${ }^{37}$.

El monasterio se ofrecía como el lugar idóneo para ser enterrado, pero también como lugar donde los monjes, gracias a las donaciones, podían proteger, cuidar e incluso admitir como familiares de la comunidad a los que lo solicitaban, cuando la concesión de bienes lleva implícito que «dan sus almas y sus cuerpos». Así lo desearon Gomicio y Mayor García en el año 1211 No cabe duda que sus cuerpos los donaron para ser enterrados en el monasterio y el alma para que a través de las oraciones se encaminaran más fácilmente hacia Dios. Devoción a Moreruela refleja Ruy Paz y Urraca Alfonso en 1262, su donación lleva implícita una promesa: hacerse familiares del monasterio y sobre todo ser enterrados en él.

En diversas ocasiones vemos que el monasterio ofrecía una seguridad material. En virtud de las donaciones, se obligaba a proteger a los donantes, especialmente en lo que atañe a aspectos de la vida como es la manutención del acogido. Numerosas referencias documentales nos dan a conocer cómo en ocasiones el monasterio prestó ayuda material a algunos de los donantes sacándoles de apuros económicos y creando en ellos una deuda de gratitud, origen de futuras donaciones.

36 A.H.N Clero Moreruela,Carpeta 3549, doc. $n^{\circ} 9$ Para llevar a cabo ese enterramiento los hermanos de Juan hicieron una donación de todo lo que tenían en Vionio y Faro, bienes que habían sido heredados de su abuela la condesa Tude. Véase mi estudio El monasterio, doc. nº 17, p. 141.

37 Isabel Alfonso ANTÓn, La colonización... documento nº 193, p. 514. 
Moreruela, monasterio que ejerció una gran influencia en el reino a lo largo de los siglos XII y XIII, pudo ser buscado como lugar de prestigio por los que se enterraron en él, pero es evidente que predominaba en la mayor parte de las donaciones la conciencia de que Moreruela era un centro de espiritualidad y de vida monástica. Entregaban sus bienes a los monjes para la oración en sufragio por los muertos y para la atención a los pobres. Había en el monasterio un enfermero de pobres. Se aceptaban además a los donantes como familiares, en caso de necesidad, enfermedad, soledad.

Este recorrido por Moreruela pretende mostrar que el monasterio fue algo más que una empresa económica y su valor sobrepasa la riqueza que creó. «Nuestra orden es ser sumisa al maestro, al abad, a la Regla, a la disciplina. Nuestra orden es amor, el silencio, ejercitarse con los ayunos, vigilias, la oración, el trabajo manual y sobre todo mantenerse en el camino más excelso: el amor. En una palabra progresar en todo esto de día en día y perseverar así hasta el final de la vida» 38 .

Este aspecto, tan importante y fundamental ha sido olvidado y no valorado por la mayor parte de los estudios que se han realizado sobre los monasterios, donde ha primado lo económico. En el monasterio viven personas que han elegido a Dios, que los buscan y esperan alcanzar su meta tras la muerte. Esta no reviste dramatismo, ni violencia, porque esa «inmutatio», según la nombra San Bernardo, pone fin a una vida de sacrificio para ir al encuentro de Dios. El monje no muere sólo. Lo rodea su comunidad. El viaje hacia la verdadera morada no deja ajenos al sentimiento, ni a los afectos. A veces la ausencia, la muerte afecta a los monjes de una forma peculiar, a pesar de que se considera que esa partida no era una pérdida. En el monasterio la muerte jamás se valora como algo que se pierde, sino que simplemente se arranca del medio para formar parte de otra vida. Es tránsito acompañado, en la intimidad de la vida espiritual. Intimidad en el acompañamiento con rezos y cánticos. En el momento del sepelio, el convento entero estará con él recitando la antífona «Clementísimo Señor, ten compasión de este pecador». Su cuerpo es conducido en procesión a la última morada material del monasterio, la más permanente: el cementerio. Ha vivido en la abnegación de sí mismo y sin nombre permanecerá enterrado. La vida del monje ha concluido y entonces es cuando se produce la unificación de toda su existencia en lo espiritual, corporal y social ${ }^{39}$.

\footnotetext{
${ }^{38}$ Carta a los monjes de Aulos que se habían afiliado al Cister, texto que nos pone en contacto con lo que era la vida real de los monjes del Cister, al menos en la época de San Bernardo y que considero que es un buen punto de referencia para llegar a esos aspectos fundamentales de una opción de vida, en este caso pertenecer a la orden cisterciense, Obras Completas, VII Cartas CXLII 510-514.

${ }^{39} \mathrm{El}$ monje que durante su vida va pasando de ala a ala, día a día, año tras año, va unificando todos los flancos de su personalidad, espiritual, psíquica, corporal y social, a través de las mil vicisitudes... J. $\mathrm{M}^{\mathrm{a}}$. DE LA TORRE, Presencia..., p. 400.
} 